\title{
The first case of primary hypertrophic osteoarthropathy with soft tissue giant tumors caused by HPGD loss-of-function mutation
}

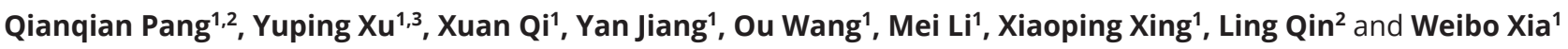 \\ ${ }^{1}$ Department of Endocrinology, Key Laboratory of Endocrinology, Ministry of Health, Peking Union Medical College Hospital, Chinese Academy of Medical \\ Sciences, Beijing, China \\ ${ }^{2}$ Musculoskeletal Research Laboratory and Bone Quality and Health Assessment Centre, Department of Orthopedics \& Traumatology, The Chinese \\ University of Hong Kong, Hong Kong SAR, Hong Kong \\ ${ }^{3}$ Department of Endocrinology, The First Affiliated Hospital of Shanxi Medical University, Taiyuan, Shanxi, China
}

Correspondence should be addressed to L Qin or W Xia: lingqin@cuhk.edu.hk or xiaweibo8301@163.com

\begin{abstract}
Background: Primary hypertrophic osteoarthropathy (PHO) is a rare genetic multi-organic disease characterized by digital clubbing, periostosis and pachydermia. Two genes, HPGD and SLCO2A1, which encodes 15-hydroxyprostaglandin dehydrogenase (15-PGDH) and prostaglandin transporter (PGT), respectively, have been reported to be related to PHO. Deficiency of aforementioned two genes leads to failure of prostaglandin E2 (PGE2) degradation and thereby elevated levels of PGE2. PGE2 plays an important role in tumorigenesis. Studies revealed a tumor suppressor activity of 15-PGDH in tumors, such as lung, bladder and breast cancers. However, to date, no HPGD-mutated PHO patients presenting concomitant tumor has been documented. In the present study, we reported the first case of HPGD-mutated PHO patient with soft tissue giant tumors at lower legs and evaluated the efficacy of selective COX-2 inhibitor (etoricoxib) treatment in the patient.

Methods: In this study, we summarized the clinical data, collected the serum and urine samples for biochemical test and analyzed the HPGD gene in our patient.

Results: A common HPGD mutation c.310_311deICT was identified in the patient. In addition to typical clinical features (digital clubbing, periostosis and pachydermia), the patient demonstrated a new clinical manifestation, a giant soft tissue tumor on the left lower leg which has not been reported in HPGD-mutated PHO patient before. After 6-month treatment with etoricoxib, the patient showed decreased PGE2 levels and improved PHO-related symptoms. Though the soft tissue tumor persisted, it seemed to be controlled under the etoricoxib treatment.

Conclusion: This finding expanded the clinical spectrum of $\mathrm{PHO}$ and provided unique insights into the HPGD-mutated PHO.
\end{abstract}
Key Words
primary hypertrophic
osteoarthropathy
- $\mathrm{PHO}$
- HPGD mutation
- soft tumor - COX2 selective inhibitor
treatment

Endocrine Connections (2019) 8, 736-744

\section{Introduction}

Primary hypertrophic osteoarthropathy (PHO; MIM 167100), also known as pachydermoperiostosis or idiopathic hypertrophic osteoarthropathy, is a rare genetic multi-organic disease characterized by digital clubbing, periostosis and pachydermia. Accompanying abnormalities include sebaceous hyperplasia, hyperhidrosis, acro-osteolysis, and effusions and pain of large joints $(1,2)$. Additional developmental anomalies, https://ec.bioscientifica.com https://doi.org/10.1530/EC-19-0149 (c) 2019 The authors Published by Bioscientifica Ltd

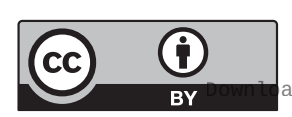

This work is licensed under a Creative Commons Attribution 4.0 International License. 
seen in a proportion of $\mathrm{PHO}$ patients, include patent ductus arteriosus and myelofibrosis $(3,4)$.

To date, two genes have been reported to be associated with PHO: hydroxyprostaglandin dehydrogenase (HPGD; MIM 601688), which encodes 15-hydroxyprostaglandin dehydrogenase (15-PGDH), and solute carrier organic anion transporter family, member 2A1 (SLCO2A1; MIM 601460), which encodes a prostaglandin transporter $(1,5)$. The pathogenesis and inherited pattern were controversial for a long time until the year 2008, and Uppal et al. identified the mutation of HPGD as the primary causative factor of PHO (1). Subsequently, Zhang et al. (5) confirmed the second gene SLCO2A1 to be responsible for PHO. According to the molecular findings, $\mathrm{PHO}$ has been categorized into two subtypes: (1) hypertrophic osteoarthropathy, primary, autosomal recessive, type 1 (PHOAR1; MIM 259100), caused by HPGD deficiency and (2) hypertrophic osteoarthropathy, primary, autosomal recessive, type 2 (PHOAR2; MIM 614441), caused by SLCO2A1 deficiency. Both HPGD and SLCO2A1 deficiency can independently lead to failure of $\mathrm{PGE}_{2}$ degradation, resulting in elevated levels of prostaglandin E2 $\left(\mathrm{PGE}_{2}\right)$ in the circulation, which is thought to contribute to the pathogenesis for $\mathrm{PHO}(1,6)$. $\mathrm{PHO}$ is a clinically heterogeneous disease. The onset age of PHO is bimodal distribution. Peaking onset age of clinical manifestations is usually the first year of life in PHOAR1 with HPGD mutations, and at puberty in PHOAR2 with SLCO2A1 mutations (6). Sefiert et al. (7) revealed that manifestations of bones and joints found in patients with homozygous mutations in the HPGD, usually appear earlier than those in the SLCO2A1, suggesting the clinical heterogeneity between the two subtypes of PHO.

It is widely acknowledged that $\mathrm{PGE}_{2}$ plays an important role in the development of tumors. $\mathrm{PGE}_{2}$ can stimulate cell proliferation, angiogenesis and motility while inhibiting apoptosis and immune surveillance $(8,9,10)$. Reduced 15-PGDH and SLCO2A1 are believed to contribute to elevated levels of $\mathrm{PGE}_{2}$ in the circulation thereby leading to the pathogenesis of these tumors $(11,12,13,14)$. However, in humans, reports of HPGD and SLCO2A1 mutation cases have only been focused on the typical features such as digital clubbing, periostosis and pachydermia. Till 2014, Guda et al. (15) reported a French-Canadian family with SLCO2A1 mutation presenting digital clubbing and early-onset colon neoplasm, suggesting a link between PHO and tumors. 15-PGDH is the major enzyme responsible for prostaglandin degradation. Numerous studies have demonstrated a tumor suppressor activity of 15-PGDH in a number of different tumors, such as lung, bladder and breast cancer $(16,17,18)$. Whereas, to date, no HPGD-mutated PHO patients presenting concomitant tumor have been documented.

Up to now, no standard treatment has been approved for PHO due to the small number of patients with PHO at most clinical centers. There are some case reports with varying therapeutic option and response, and the treatments are mostly focused on alleviation of symptoms, including nonsteroidal anti-inflammatory drugs (NSAIDS), pamidronate and tamoxifen citrate to relieve painful osteoarthropathy $(19,20)$. Given that the increased circulating $\mathrm{PGE}_{2}$ levels is responsible for pathogenic mechanism of PHO, cyclo-oxygenase (COX) inhibition may represent a targeted therapeutic option. Recently, COX-2 selective inhibitors, which inhibit the COX-2 enzyme and thereby suppress $\mathrm{PGE}_{2}$ biosynthesis, represent promising treatment options for PHO. A few studies have shown that etoricoxib, a novel COX-2 selective inhibitor, has a positive therapeutic effect on $\mathrm{PHO}$ patients in terms of decreased urinary $\mathrm{PGE}_{2}$ levels and improvement of clinical phenotypes including pachydermia, clubbing finger and joint swelling $(21,22,23)$.

Here we reported the first case of a Chinese HPGD-mutated PHO patient with soft tissue giant tumors at bilateral lower legs, as well as evaluated the efficacy of selective COX-2 inhibition (etoricoxib) treatment in this patient.

\section{Methods and materials}

\section{Human subjects}

This study was approved by the Local Ethics Committee of the Department of Scientific Research at Peking Union Medical College Hospital (PUMCH). The Chinese PHO patient signed informed consent documents before entering the study.

\section{Biochemical parameters}

The patient was admitted into our hospital and went through detailed clinical, biochemical and radiographic investigation. For biochemical analysis, fasting blood samples and 24-h urine were collected. Serum calcium (Ca), serum phosphate $(\mathrm{Pi})$, serum alkaline phosphatase (ALP), serum creatinine ( $\mathrm{SCr}$ ), erythrocyte sedimentation rate (ESR), hypersensitive $\mathrm{C}$ reactive protein (hsCRP), interleukin 6 (IL-6) and tumor necrosis factor- $\alpha$ (TNF- $\alpha$ ) were measured spectrophostometrically using routine

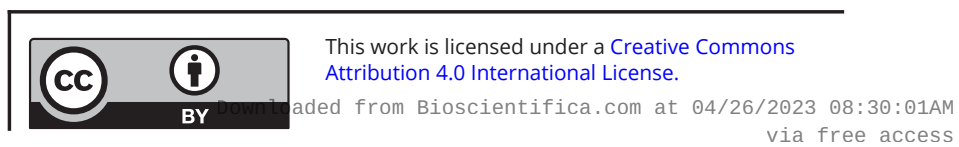


assays available at the central laboratory of PUMCH. Serum intact parathyroid hormone (iPTH) and beta- C-terminal telopeptide of type I collagen ( $\beta$-CTX) were measured by an automated Roche electrochemiluminescence system (Roche Diagnostics). Serum and urinary $\mathrm{PGE}_{2}$ and PGEM (a metabolite of $\mathrm{PGE}_{2}$ ) levels were measured by competitive enzyme-linked immunosorbent assay (ELISA) according to the manufacturer's instructions (Cayman Chemicals). The measuring ranges of ESR, hsCRP, IL-6, TNF- $\alpha$, PTH, $\beta$-CTX, PGE ${ }_{2}$ and PGEM were $1-140 \mathrm{~mm} / \mathrm{h}, 0.15-20 \mathrm{mg} / \mathrm{L}$, $2-1000 \mathrm{pg} / \mathrm{mL}, \quad 1.7-1000 \mathrm{pg} / \mathrm{mL}, \quad 1.2-5000 \mathrm{pg} / \mathrm{mL}$, $0.01-6.00 \mathrm{ng} / \mathrm{mL}, \quad 7.8-1000 \mathrm{pg} / \mathrm{mL}$ and $0.39-50 \mathrm{pg} / \mathrm{mL}$, respectively. The intra-assay coefficients of variation were $<5 \%$ for ESR, $0.7 \%$ for hsCRP, 3.5-6.2\% for IL-6, 2.6-3.6\% for TNF- $\alpha, 1.2 \%$ for iPTH, $2.0 \%$ for $\beta$-CTX, 3.7\% for PGE PG $_{2}$ and $5.5 \%$ for PGEM.

\section{Imaging techniques}

$\mathrm{X}$-ray radiography of both hands and legs were performed to assess bony deformities. Magnetic resonance imaging (MRI) of the bilateral legs was performed to confirm the $\mathrm{X}$-ray findings and evaluate the giant tumors at patient's lower legs. Computed tomographic angiography (CTA, SOMATON Force, Siemens Healthineers) was conducted at the tumor sites to clarify the tumor source and vascular perfusion.

\section{Area bone mineral densities (BMD)}

Area bone mineral densities of lumbar spine and proximal femur were measured with a dual energy X-ray absorptiometry (Prodigy Advance, GE Lunar Corporation).

\section{Mutational analysis}

Whole blood was obtained from the patient. Genomic DNA was extracted from peripheral white blood cells using the DNA Extraction Kit (QIAamp DNA, Qiagen) according to the manufacturer's instructions. The seven exons of HPGD were amplified through PCR with a set of primers designed by Gene Runner Primer Analysis Software (Supplementary Table 1, see section on supplementary data given at the end of this article). The amplified products were sequenced by an automated sequencer (ABI 373XL sequencer, Applied Biosystems) according to the manufacturer's recommendation. Putative mutations were analyzed and compared using the Basic Local Alignment Search Tool (Blast).

\section{Bioinformatics analysis}

The identified mutation in HPGD gene was analyzed at the protein level. Protein modeling was conducted based on the data of 15-PGDH structure in Protein Date Bank (PDB ID: 2GDZ, http://www.rcsb.org), and the mutationalrelated residues were positioned in the constructed 3D structural model (24) using the PyMOL Viewer 1.8.6 (free download from https://pymolwiki.org).

\section{Results}

\section{Clinical findings}

The 41-year-old patient was born to healthy consanguineous parents. Widening of distal phalanges of fingers, hyperhidrosis of hands and facial furrowing were noted during infancy. He complained of frequent pain in bilateral knees after having a cold. From the age of 35 years, he had swelling in knees and ankles but denied any bone pain. One year later, he noticed a soft tumor at his left leg, and the size of the tumor increased rapidly in the following years. At the age of 41 years, he was admitted to our clinic with complains of a giant tumor at left leg. Physical examination showed digital clubbing (Fig. 1A), oily, thickened and furrowed face (Fig. 1B), palmoplantar hyperhidrosis and palmoplantar hyperkeratosis. Swelling was found in bilateral wrists and knees (circumference of left and right knee was $37.0 \mathrm{~cm}$ and $38.0 \mathrm{~cm}$, respectively). He suffered from a total of three soft tumors at bilateral legs, and the most giant one located at left lower leg $(10 \times 12 \mathrm{~cm}$, circumference $44.5 \mathrm{~cm})$, and the other two smaller tumors located at right lower leg (Fig. 1C). He had no cardiac, pulmonary, hepatic disease, as well as delayed closure of cranial suture, anemia or hypoalbuminemia. He denied any gastrointestinal discomfort. The laboratory findings were shown in Table 1 . Area bone density of lumbar spine and proximal femur were in normal range. Radiological examination of both hands and legs showed acro-osteolysis on distal phalanges of fingers (Fig. 2A) and periostosis along long bones (Fig. 2B and C). Besides, $\mathrm{X}$-ray of bilateral legs revealed massive soft tissue swelling of calf (Fig. 2B and C). MRI of legs confirmed the plain radiographic findings and also showed subchondral cysts, diffuse synovial hypertrophy and effusion in bilateral knees (Fig. 2D and E). Additionally, MRI imaging showed round hyperdense foci around medial of the midshaft of the left tibia $(6.2 \times 11.2 \times 10.6 \mathrm{~cm})$, as well as round hyperdense foci at the right upper fibular

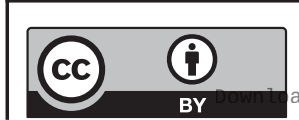

This work is licensed under a Creative Commons Attribution 4.0 International License. ded from Bioscientifica.com at 04/26/2023 08:30:01AM 

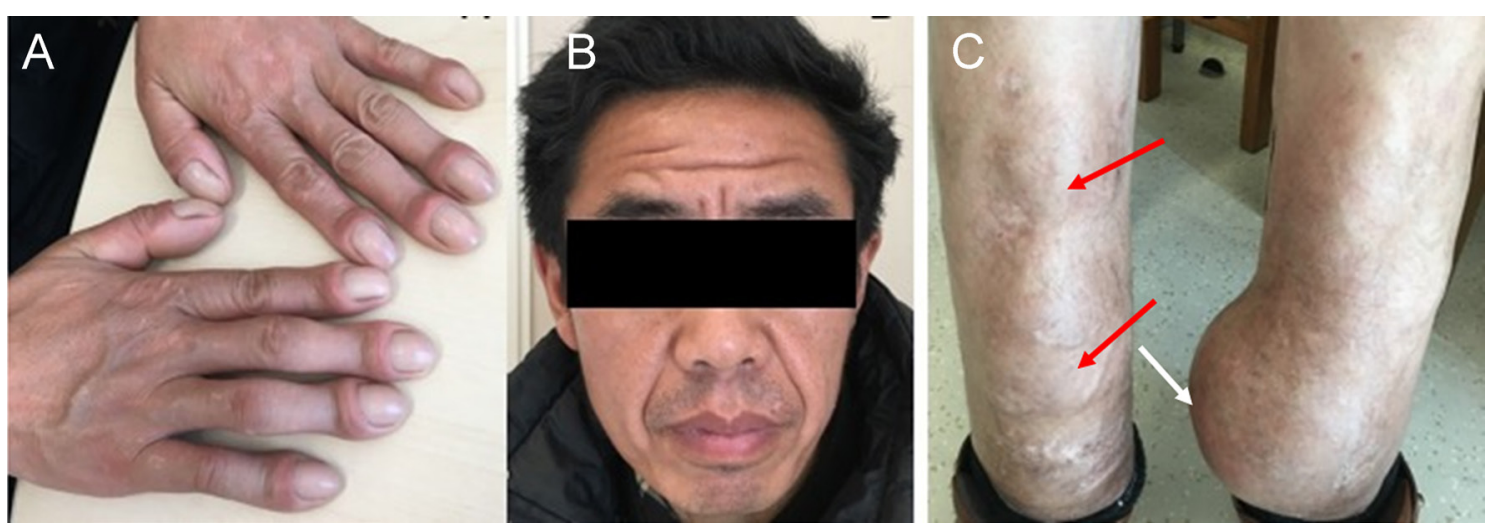

\section{Figure 1}

The clinical features of the HPGD-mutated PHO patient. (A). Digital clubbing. (B) Oily, thickened and furrowed face. (C) A soft tissue giant tumor on the left lower leg (white arrow), two smaller tumors on the right leg (red arrow).

$(1.0 \times 1.2 \mathrm{~cm})($ Fig. $2 \mathrm{~F})$. CTA revealed the calcified soft tissue mass at medialis of bilateral legs. The biggest one was at left $(11.3 \times 5.5 \mathrm{~cm})$, indicating that the tumor was soft tissue source (Fig. 2G and H). Vascular perfusion of bilateral legs was normal (Fig. 2I). The patient conducted tumor biopsies in local hospital (The Third Hospital of Hebei Medical University) before he was admitted to our department for medical consulting.

Table 1 Laboratory findings of the PHO patient before and after etoricoxib treatment.

\begin{tabular}{|c|c|c|c|}
\hline & $\begin{array}{l}\text { Before } \\
\text { treatment }\end{array}$ & $\begin{array}{c}\text { After } \\
\text { treatment }\end{array}$ & $\begin{array}{l}\text { Reference } \\
\text { range }\end{array}$ \\
\hline \multicolumn{4}{|c|}{ Routine biochemical markers } \\
\hline ALT (U/L) & 44 & 16 & $9-50$ \\
\hline $\mathrm{SCr}(\mu \mathrm{mol} / \mathrm{L})$ & 68 & 62 & $59-104$ \\
\hline $\mathrm{Ca}(\mathrm{mmol} / \mathrm{L})$ & 2.22 & 2.17 & $2.13-2.70$ \\
\hline $\mathrm{Pi}(\mathrm{mmol} / \mathrm{L})$ & 1.16 & 1.02 & $0.81-1.45$ \\
\hline $\operatorname{ALP}(U / L)$ & 130 & 102 & $45-125$ \\
\hline iPTH (pg/mL) & 56.3 & 47.9 & $12-65$ \\
\hline$\beta$-CTX (ng/mL) & 0.827 & 0.654 & $0.26-0.512$ \\
\hline \multicolumn{4}{|l|}{ Inflammatory cytokines } \\
\hline $\operatorname{ESR}(\mathrm{mm} / \mathrm{h})$ & 6 & NA & $0-15$ \\
\hline hsCRP (mg/L) & 33.4 & 0.78 & $0-3$ \\
\hline IL-6 (pg/mL) & 9.0 & 2.0 & $<5.9$ \\
\hline TNF- $\alpha(\mathrm{pg} / \mathrm{mL})$ & 4.7 & 4.8 & $<8.1$ \\
\hline \multicolumn{4}{|c|}{ Specific biochemical markers } \\
\hline Serum PGE2 (pg/mL) & 316 & 231 & $28.7-308.2(26)$ \\
\hline Serum PGEM (pg/mL) & 13.3 & 24.1 & $0.5-17.2(26)$ \\
\hline $\begin{array}{l}\text { Urinary PGE2 } \\
\text { (ng/mmol cr) }\end{array}$ & 618 & 215 & $36.4-85.5(25)$ \\
\hline $\begin{array}{l}\text { Urinary PGEM } \\
\text { (ng/mmol cr) }\end{array}$ & 4.27 & 3.27 & $23-52.8(25)$ \\
\hline \multicolumn{4}{|c|}{$\begin{array}{l}\text { Abnormal findings were indicated in bold. } \\
\text { ALP, serum alkaline phosphatase; ALT, alanine aminotransferase; } \\
\beta \text {-CTX, beta-C-terminal telopeptide of type I collagen; Ca, calcium; ESR, } \\
\text { erythrocyte sedimentation rate; hsCRP, hypersensitive C reactive protein; } \\
\text { IL-6, interleukin 6; NA, not available; Pi, phosphate; PTH, parathyroid } \\
\text { hormone; Scr, serum creatinine; TNF- } \alpha \text {, tumor necrosis factor- } \alpha \text {. }\end{array}$} \\
\hline
\end{tabular}

Histological evaluation of the tumor tissue revealed a benign tumor with irregularly curved immature woven bone trabeculae and proliferative fibrous granulation tissues invading among the trabecular bones (Fig. 3). PHO diagnosis was made by typical features including digital clubbing, hyperhidrosis, periostosis and acro-osteolysis, as well as the increased levels of serum $\mathrm{PGE}_{2}$. The patient has two siblings, and all of his relatives were healthy without any typical PHO symptoms.

\section{The treatment of patient}

The patient was treated with selective COX-2 inhibitor (etoricoxib, $60 \mathrm{mg}$ once daily, Merk Sharp \& Dohme Corp USA) and re-evaluated at the time point of 6 months. After re-evaluation, we found etoricoxib treatment led to the reduction of swelling in knees (circumference decreased from 38 to $37.1 \mathrm{~cm}$ ) and ankles than it was before etoricoxib treatment, though facial furrowing appearance persisted. The soft tissue mass in bilateral legs persisted but did not evolve since etoricoxib treatment. Serum and urinary $\mathrm{PGE}_{2}$ levels, inflammatory cytokines and bone turnover markers all decreased after treatment. The levels of the biochemical markers before and after treatment were shown in Table 1. MRI of the bilateral knees showed remission of synovitis.

\section{Mutational analysis of HPGD}

Direct sequencing of genomic DNA indicated that the patient carried a homozygous mutation c.310_311delCT. This mutation caused frameshift after 103T and created a premature TAA stop signal at codon 106 which resulted in a truncated protein. The mutation-related residues (103T)

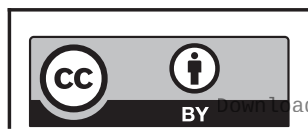

This work is licensed under a Creative Commons Attribution 4.0 International License. 

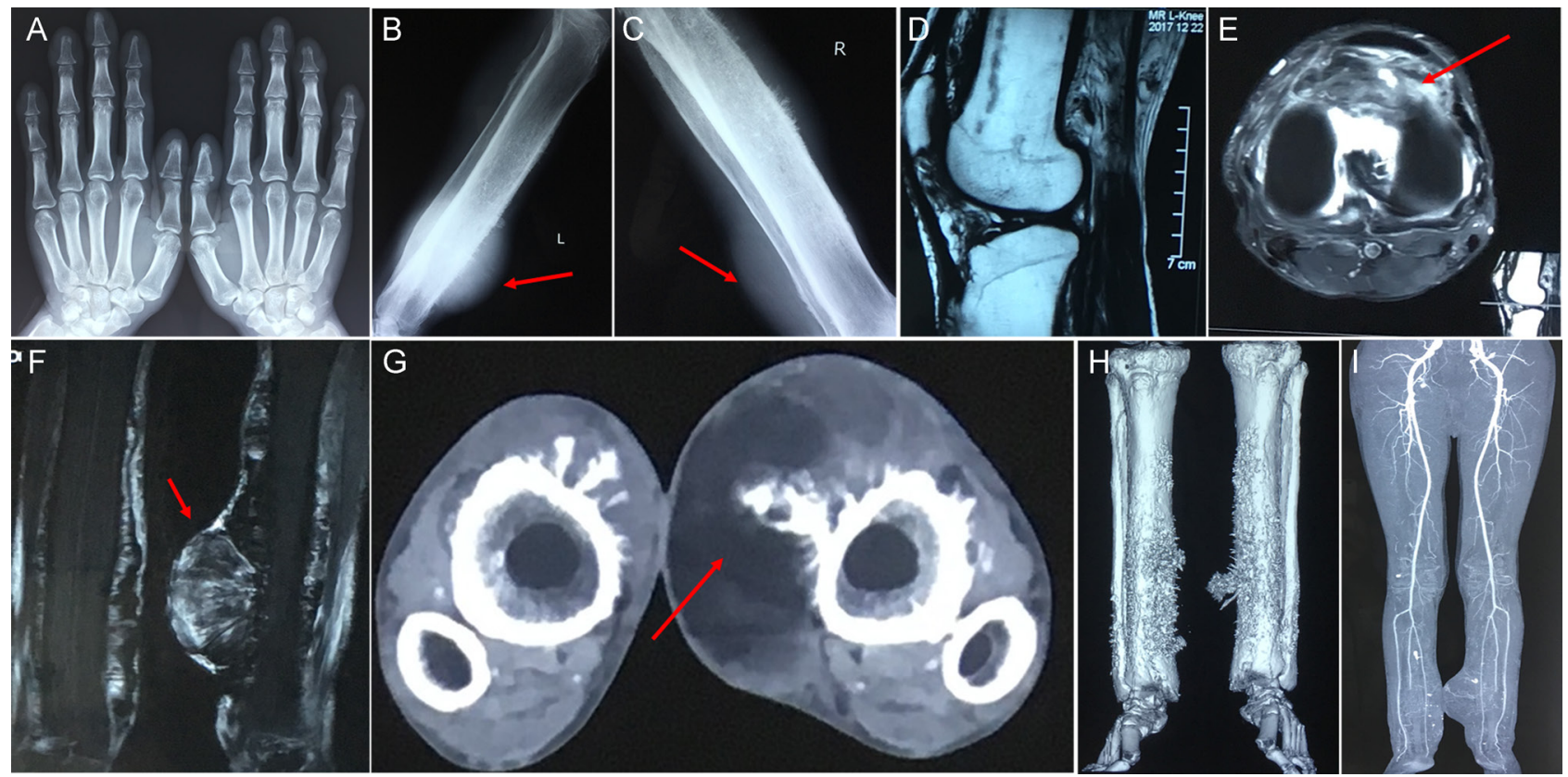

\section{Figure 2}

The radiographic signatures of the HPGD-mutated PHO patient. (A and C) X-ray examination of hands and bilateral knees. (A) Acro-osteolysis on distal phalanges of the fingers. (B and C) Cortical thickening and periostosis in the long bones, as well as the soft tissue swelling on the lower legs (red arrows). (D and E) MRI examination of bilateral legs. (D) Thickening of cortical bones and bone marrow edema in femurs and tibias. (E) Diffuse synovial hypertrophy and effusion in knee joint (red arrow). (F) An extra-articular diffuse tumor of the medialis of left tibia $(6.2 \times 11.2 \times 10.6 \mathrm{~cm})(\mathrm{red}$ arrow). ( $\mathrm{G}$ and H) CTA examination of bilateral legs. (G) Calcified soft tissue mass in the legs bilaterally, the biggest was in the left $(11.3 \times 5.5 \mathrm{~cm})(\mathrm{red}$ arrow). (I) Normal vascular perfusion of bilateral legs. And no increased vascularity was found inside the giant tumor.

and predicted truncated protein of $H P G D$ gene were shown in Fig. 4. The deletion c.310_311delCT has been reported in some Asian PHO families $(19,22,25)$, which seems to be a hotspot mutation in Asian PHO patients.

\section{Discussion}

PHO is a rare genetic disease featured by digital clubbing, periostosis, pachydermia and acro-osteolysis, which has been linked to the failure of prostaglandin metabolism. Defects of two genes have been confirmed to be responsible for this disease: HPGD and SLCO2A1, which encodes 15-PGDH and prostaglandin transporter (PGT), respectively $(1,5)$. Under normal conditions, $\mathrm{PGE}_{2}$ is metabolized and cleared through two main steps: (1) selective uptake of $\mathrm{PGE}_{2}$ across the plasma membrane by PGTs, including SLCO2A1, SLCO3A1, SLCO4A1. (2) degradation of $\mathrm{PGE}_{2}$ inside the cell by 15-PGDH into PGEM (26). 15-PGDH is the main enzyme in prostaglandin metabolism. Patients with HPGD loss-of-function mutations present elevated $\mathrm{PGE}_{2}$ levels $(1,27)$. Consistently, in the current study, our patient showed an increased level of serum and urinary $\mathrm{PGE}_{2}$ (Table 1).

To date, HPGD mutations have been reported in 47 families, of which 20 were from Southern or Western Asia $(1,3,19,27,28,29,30)$. In the present study,
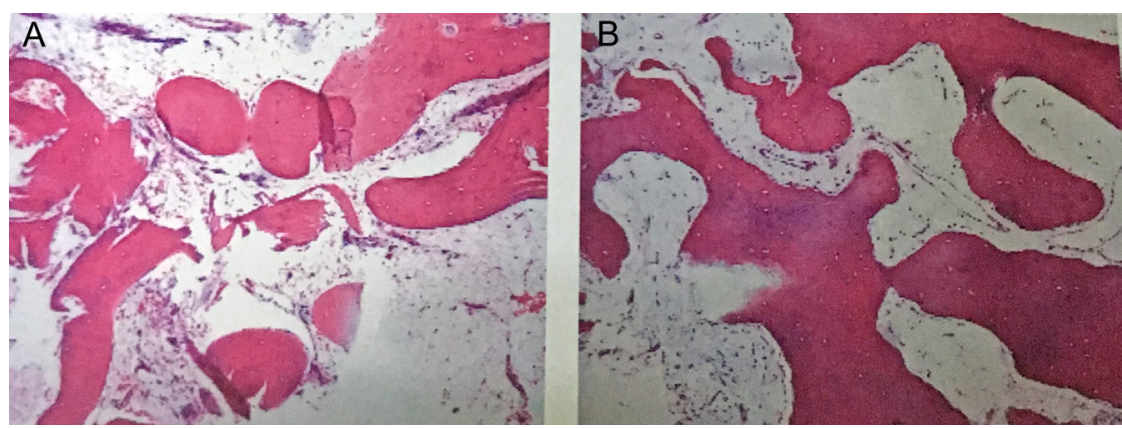

\section{Figure 3}

Histological images analysis. Photomicrograph of the tissue tumor obtained from the left leg ( $A$ and B) showing irregularly curved immature woven bone trabeculae with more dense proliferative fibrous granulation tissues invading among the trabecular bones. Soft tissue ossification was also found in this tissue but without evidence of a malignant neoplasm (HE staining: $0 \times$ ).

https://ec.bioscientifica.com https://doi.org/10.1530/EC-19-0149 (c) 2019 The authors Published by Bioscientifica Ltd

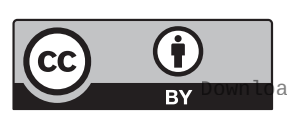

This work is licensed under a Creative Commons Attribution 4.0 International License. ded from Bioscientifica.com at 04/26/2023 08:30:01AM 


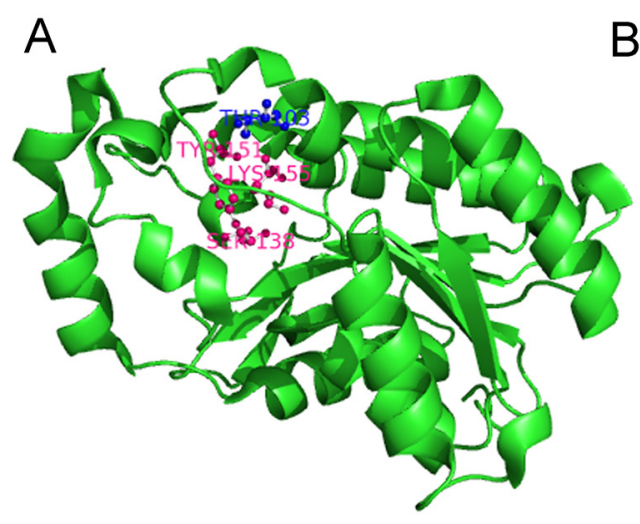

B

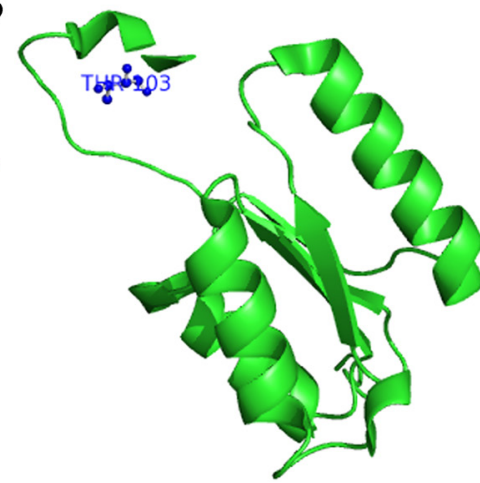

Figure 4

The 3D structure of human wide type and mutated 15-PGDH protein. (A) The 3D structure of human 15-PGDH protein was constructed by Niesen et al. (24), in which the deletion mutationrelated residues (103T) and active sites Ser138, Tyr151 and Lys155 were labeled blue and violet, respectively. (B) The 3D structure of mutated 15-PGDH protein. The deletion c.310_311delCT mutation caused the frameshift after $103 \mathrm{~T}$ and a premature stop at codon 106, leading to a truncated protein and 160 amino acids lacking. a previously known HPGD mutation (c.310_311delCT) was identified in our patient. The mutation c.310_311delCT, which contributed to a frameshift after codon 104 and resulted in the loss of protein acceptor site as well as the putative substrate-binding site, is currently considered to be the most common mutation in Asian familial cases (19). In Yuan's study, this common mutation was found in all the nine reported Chinese patients, indicating the high frequency of c.310_311delCT mutation in Chinese PHO patients (25).

The HPGD gene encodes a helical protein, consists of 266 amino acids, which belongs to the member of the short-chain dehydrogenase family (SDR) family (31). Generally, SDRs are divided into two larger families, 'classical' with 250-odd residues and 'extended' with 350-odd residues. 15-PGDH belongs to the 'classical' SDR family. Specifically, the structure of 15-PGDH (the 'classical' SDR enzyme) includes N-terminal transmembrane domains, C-terminal transmembrane domains, nucleotide-binding region, active site, central $\beta$-sheet and the helix. Previous studies have revealed that the active sites Ser138, Tyr151 and Lys155 are the most conserved residues essential for catalytic activity of 15-PGDH. Tyr151 functions as the catalytic base, whereas Ser138 stabilizes the substrates, and Lys155 forms hydrogen bonds with the nicotinamide ribose moiety to promote proton transfer $(32,33)$. Niesen et al. (24) have constructed a 3D structure of human 15-PGDH by homology modeling technique. The deletion mutation c.310_311delCT encodes a truncated protein lacking 160 amino acids of the C-terminal domain, which might interfere the stability and function of 15-PGDH structure. Ultimately, this mutation would result in loss of function of the enzyme since the most important residues (Ser 138, Tyr151 and Lys155) were all absent from the protein (Fig. 4). In view of the fact that $15-\mathrm{PGDH}$ is the main enzyme in prostaglandin metabolism, the alteration of the 15-PGDH structure may be the cause of the variations in clinical phenotypes in $\mathrm{PHO}$ patients.

We reviewed all 51 HPGD mutant patients (PHOAR1) reported before and found almost all of these PHOAR1 patients have digital clubbing (50/51, 98\%) and periostosis (51/51, 100\%). Besides, accompanying abnormalities such as hyperhidrosis $(41 / 51,80.4 \%)$, joint swelling $(30 / 51$, $58.8 \%$ ), various forms of pachydermia (28/51, 54.9\%) and arthralgia $(22 / 51,43.1 \%)$ have also been seen in a proportion of the PHOAR1 patients $(1,21,22,23,25,29,34$, $35,36)$. Consistent with Hou's study (27), gastrointestinal complications, peptic ulcer, chronic gastritis, anemia and myelofibrosis which were only presented in PHOAR2 patients, were absent in these PHOAR1 patients. In keeping with previous findings of the reported HPGD-mutated patients, the dermatoskeletal features of the patient in this study were typical for PHOAR1. The patient presented an early-onset age in infancy, which was similar to those extensively reported in previous HPGD-mutated PHO patients (6). Additionally, the patient had typical phenotypes of digital clubbing, periostosis, pachydermia, hyperhidrosis and arthropathy but denied any gastrointestinal complications, peptic ulcer, chronic gastritis, anemias and myelofibrosis syndromes.

It was well known that $\mathrm{PGE}_{2}$ could stimulate the activity of both osteoclasts and osteoblasts, causing the enhancement of bone resorption and new bone formation, which might be related to PHO skeletal manifestations such as acro-osteolysis and periostosis (1). Jajic et al. (37) reviewed all of the reported $76 \mathrm{PHO}$ patients and found all of these patients had periosteal reaction along the long bones and $23.7 \%$ of these patients had acro-osteolysis. Because the levels of bone turnover markers were not investigated in these patients, the association between $\mathrm{PGE}_{2}$ and bone homeostasis were still unknown in PHO patients. In our study, the patient showed acro-osteolysis at distal phalanges of the fingers (Fig. 2A) and periostosis https://ec.bioscientifica.com https://doi.org/10.1530/EC-19-0149 (c) 2019 The authors Published by Bioscientifica Ltd

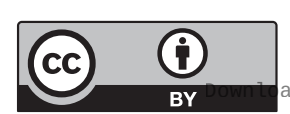

This work is licensed under a Creative Commons Attribution 4.0 International License. ded from Bioscientifica.com at 04/26/2023 08:30:01AM 
at the shafts of tubular bones (Fig. 2B and C). Biochemical test of the patient showed elevated levels of $\beta$-CTX and ALT. Skeletal X-ray findings in combination with the increased levels of bone turnover markers, suggested that though area bone mineral densities (aBMD) were within the normal range, there might be still some skeletal changes independent of aBMD measured by DXA in PHO patients.

As discussed earlier, nearly half of PHOAR1 patients presented osteoarticular manifestations, including joint swelling (30/51, 58.8\%) and arthralgia (22/51, 43.1\%), but joint impairment assessment through radiographic imaging of these patients was lacking. Literature review provides MRI examination results in six $\mathrm{PHO}$ patients, but the regions of interest (ROI) of MRI were focused on the bones rather than the joints. Pineda et al. (38) demonstrated remodeling and thickening of cortical bone and tortuous intraosseous vascular channels. Adams et al. (34) found transverse long bone expansion with periosteal thickening using gadolinium-enhanced MR images. In the present study, MRI of bilateral legs was performed in the PHO patient. Both bones and joints were scanned and evaluated in the MRI examination and the results showed thickening of cortical bones and bone marrow edema in femurs and tibias (Fig. 2D). Moreover, joint swelling, subchondral cysts, diffuse synovial hypertrophy and effusion were also seen in knee joint (Fig. 2E), suggesting joint impairment of the patient.

It is worth mentioning that the patient had soft tissue tumors at bilateral lower legs, which has not been reported in PHOAR1 patients before. Studies have revealed that 15-PGDH expression was reduced in colon, breast, gastric and lung cancers and restoration of 15-PGDH could inhibit tumorigenesis in xenografts, indicating that 15-PGDH was a tumor suppressor in these tumors as well as played an essential role in regulating tumor development and progression $(16,17,18)$. A work from Rogenski's laboratory (17) showed that 15-PGDH knockdown in 9027 shRNA lentivirus-infected RT4 cells permitted $\mathrm{PGE}_{2}$ signaling as measured by cAMP generation, whereas signaling was suppressed in the 15-PGDH-ex-pressing parental lines, demonstrating that 15 -PGDH had a direct impact on PGE $_{2}$ signaling in cancer cells. Numerous studies have already revealed an important link between elevated levels of $\mathrm{PGE}_{2}$ and tumor development and progression, suggesting there was a potential relationship between $\mathrm{PHO}$ and tumors $(8,9,10)$. However, up to now, there was only one SLCO2A1-mutated patient reported to suffer from colon neoplasm (15). In this study, we reported the first case of HPGD-mutated
PHO patient, presenting typical PHO features and atypical soft tissue tumors at bilateral lower legs. It was well known that the effects of $\mathrm{PGE}_{2}$ were mediated via four known receptors EP1, EP2, EP3 and EP4 in individual target cell, involving in cell proliferation, apoptosis and angiogenesis (39). EP-related signaling seemed to play a key role in tumorigenesis. Most recently, via using mPGES1-deficient mice, PTGER4-deficient mice and specific antagonists of EPs, a study from Inada's laboratory (40) assessing the role of $\mathrm{PGE}_{2}$ in the soft tissue tumors revealed that $\mathrm{PGE}_{2}$ acted on fibroblasts in tumor microenvironment through EP4 receptor. Besides, this research group also demonstrated that tumor growth and vascularization in soft tissues were abrogated by an EP4 receptor antagonist, suggesting $\mathrm{PGE}_{2} / \mathrm{EP} 4$ signaling played a critical role in the growth of tumors. Unfortunately, since the patient refused tumor biopsies in our department, the in vitro experiment was not available in this study. Whether $\mathrm{PGE}_{2} / \mathrm{EP} 4$ signaling involved and played a critical role in the tumorigenesis of this PHO patient remained unclear. Notably, radiographic examinations, especially CTA of lower legs, suggested benign soft tissue tumors as there was no increased vascularity and abnormal vascular perfusion found inside the giant tumor (Fig. 2I).

Studies concerning the treatment of $\mathrm{PHO}$ patients were limited and no treatment has been shown to reverse the hypertrophic bone changes. Currently, the most commonly used drugs were NSAIDS, since they were effective in alleviating arthritis and easing bone pain. Recently, the novel selective COX-2 inhibitors, etoricoxib, which not only suppress COX-2-derived $\mathrm{PGE}_{2}$ synthesis and lower $\mathrm{PGE}_{2}$ levels from upstream, but also improve biochemical selectivity over that of other selective COX-2 inhibitors $(41,42)$, has been shown to have a positive therapeutic effect on $\mathrm{PHO}$ patients in some clinical studies $(21,23)$. Indeed, the serum and urinary $\mathrm{PGE}_{2}$ in our patient were decreased after 6-month etoricoxib treatment, confirming its efficacy to treat this disease based on pathogenic considerations. The PHO-related symptoms including joint swelling and hyperhidrosis, as well as the increased biochemical markers including ALP, $\beta$-CTX, hsCRP and IL-6 have also been markedly improved within 6 months. These findings were in agreement with the Li and Yuan's study $(21,23)$. Interestingly, though the soft tissue tumor persisted, it has not grown since COX-2 inhibitor treatment, indicating the $\mathrm{PGE}_{2}$ might play a central role in tumor progression of $\mathrm{PHO}$ patient.

In summary, in the present study, we reported for the first time a Chinese Han PHO patient with soft tissue giant tumors in lower legs. Mutational analysis

This work is licensed under a Creative Commons Attribution 4.0 International License. ded from Bioscientifica.com at 04/26/2023 08:30:01AM 
of the patient revealed a common homozygous mutation c.310_311delCT in HPGD gene. In addition to typical clinical features including digital clubbing, periostosis, pachydermia and acro-osteolysis, the patient presented an atypical manifestation, giant soft tissue tumors at both lower legs which have not been reported in HPGDmutated PHO patient before. After six-month treatment with a novel selective COX-2 inhibitor, etoricoxib $(60 \mathrm{mg}$ once daily), $\mathrm{PGE}_{2}$ levels were markedly decreased and PHO-related symptoms such as pachydermia, joint swelling and hyperhidrosis significantly improved in this patient. Though the soft tissue tumors persisted, it seemed to be controlled under the etoricoxib treatment. Further studies and investigations should be performed to reveal the role of $\mathrm{PGE}_{2}$ signaling on tumorigenesis in $\mathrm{PHO}$.

\section{Supplementary data}

This is linked to the online version of the paper at https://doi.org/10.1530/ EC-19-0149.

\section{Declaration of interest}

The authors declare that there is no conflict of interest that could be perceived as prejudicing the impartiality of the research reported.

\section{Funding}

This study was supported by the National Natural Science Foundation of China (Grant number: 81471088 and 81670714).

\section{Acknowledgments}

The authors would like to thank the subjects for consenting to participate in this study. Prof. Weibo Xia was responsible for study design. Qianqian Pang performed the study and prepared the first draft of the paper. Qianqian Pang and Yuping Xu contributed to the clinical and experimental work. Qianqian Pang and Dr Xuan Qi were responsible for the statistical analysis of the data. All of the authors contributed to revise the paper critically for intellectual content and approved the final version of the submitted manuscript.

\section{References}

1 Uppal S, Diggle CP, Carr IM, Fishwick CW, Ahmed M, Ibrahim GH, Helliwell PS, Latos-Bielenska A, Phillips SE, Markham AF, et al. Mutations in 15-hydroxyprostaglandin dehydrogenase cause primary hypertrophic osteoarthropathy. Nature Genetics 200840 789-793. (https://doi.org/10.1038/ng.153)

2 Sasaki T, Niizeki H, Shimizu A, Shiohama A, Hirakiyama A, Okuyama T, Seki A, Kabashima K, Otsuka A, Ishiko A, et al. Identification of mutations in the prostaglandin transporter gene SLCO2A1 and its phenotype-genotype correlation in Japanese patients with pachydermoperiostosis. Journal of Dermatological Science 201268 36-44. (https://doi.org/10.1016/j.jdermsci.2012.07.008)

3 Seifert W, Beninde J, Hoffmann K, Lindner TH, Bassir C, Aksu F, Hubner C, Verbeek NE, Mundlos S \& Horn D. HPGD mutations cause cranioosteoarthropathy but not autosomal dominant digital clubbing. European Journal of Human Genetics 200917 1570-1576. (https://doi.org/10.1038/ejhg.2009.104)

4 Diggle CP, Parry DA, Logan CV, Laissue P, Rivera C, Restrepo CM, Fonseca DJ, Morgan JE, Allanore Y, Fontenay M, et al. Prostaglandin transporter mutations cause pachydermoperiostosis with myelofibrosis. Human Mutation 201233 1175-1181. (https://doi. org/10.1002/humu.22111)

5 Zhang Z, Xia W, He J, Zhang Z, Ke Y, Yue H, Wang C, Zhang H, Gu J, $\mathrm{Hu}$ W, et al. Exome sequencing identifies SLCO2A1 mutations as a cause of primary hypertrophic osteoarthropathy. American Journal of Human Genetics 201290 125-132. (https://doi.org/10.1016/j. ajhg.2011.11.019)

6 Zhang Z, He JW, Fu WZ, Zhang CQ \& Zhang ZL. Mutations in the SLCO2A1 gene and primary hypertrophic osteoarthropathy: a clinical and biochemical characterization. Journal of Clinical Endocrinology and Metabolism 201398 E923-E933. (https://doi. org/10.1210/jc.2012-3568)

7 Seifert W, Kuhnisch J, Tuysuz B, Specker C, Brouwers A \& Horn D. Mutations in the prostaglandin transporter encoding gene SLCO2A1 cause primary hypertrophic osteoarthropathy and isolated digital clubbing. Human Mutation 201233 660-664. (https://doi. org/10.1002/humu.22042)

8 Wang D \& Dubois RN. Prostaglandins and cancer. Gut 200655 115-122. (https://doi.org/10.1136/gut.2004.047100)

9 Reader J, Holt D \& Fulton A. Prostaglandin E2 EP receptors as therapeutic targets in breast cancer. Cancer Metastasis Reviews 2011 30 449-463. (https://doi.org/10.1007/s10555-011-9303-2)

10 Menter DG \& Dubois RN. Prostaglandins in cancer cell adhesion, migration, and invasion. International Journal of Cell Biology 2012 2012 723419. (https://doi.org/10.1155/2012/723419)

11 Holla VR, Backlund MG, Yang P, Newman RA \& DuBois RN. Regulation of prostaglandin transporters in colorectal neoplasia. Cancer Prevention Research 20081 93-99. (https://doi. org/10.1158/1940-6207.CAPR-07-0009)

12 Markowitz SD. Colorectal neoplasia goes with the flow: prostaglandin transport and termination. Cancer Prevention Research 20081 77-79. (https://doi.org/10.1158/1940-6207.CAPR-08-0009)

13 Backlund MG, Mann JR, Holla VR, Buchanan FG, Tai HH, Musiek ES, Milne GL, Katkuri S \& DuBois RN. 15-Hydroxyprostaglandin dehydrogenase is down-regulated in colorectal cancer. Journal of Biological Chemistry 2005280 3217-3223. (https://doi.org/10.1074/ jbc.M411221200)

14 Yan M, Rerko RM, Platzer P, Dawson D, Willis J, Tong M, Lawrence E, Lutterbaugh J, Lu S, Willson JK, et al. 15-Hydroxyprostaglandin dehydrogenase, a COX-2 oncogene antagonist, is a TGF-beta-induced suppressor of human gastrointestinal cancers. PNAS $2004 \mathbf{1 0 1}$ 17468-17473. (https://doi.org/10.1073/pnas.0406142101)

15 Guda K, Fink SP, Milne GL, Molyneaux N, Ravi L, Lewis SM, Dannenberg AJ, Montgomery CG, Zhang S, Willis J, et al. Inactivating mutation in the prostaglandin transporter gene, SLCO2A1, associated with familial digital clubbing, colon neoplasia, and NSAID resistance. Cancer Prevention Research 20147 805-812. (https://doi.org/10.1158/1940-6207.CAPR-14-0108)

16 Li Y, Li S, Sun D, Song L \& Liu X. Expression of 15-hydroxyprostaglandin dehydrogenase and cyclooxygenase-2 in non-small cell lung cancer: correlations with angiogenesis and prognosis. Oncology Letters 20148 1589-1594. (https://doi. org/10.3892/ol.2014.2371)

17 Tseng-Rogenski S, Gee J, Ignatoski KW, Kunju LP, Bucheit A, Kintner HJ, Morris D, Tallman C, Evron J, Wood CG, et al. Loss of 15-hydroxyprostaglandin dehydrogenase expression contributes to bladder cancer progression. American Journal of Pathology 2010176 1462-1468. (https://doi.org/10.2353/ajpath.2010.090875)

18 Zhang B, Ma X, Li Z, Gao X, Wang F, Liu L, Shen G, Sang Y, Li M, Li Y, et al. Celecoxib enhances the efficacy of 15-hydroxyprostaglandin dehydrogenase gene therapy in treating

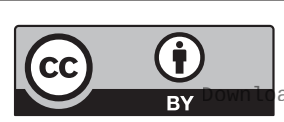

This work is licensed under a Creative Commons Attribution 4.0 International License. 
murine breast cancer. Journal of Cancer Research and Clinical Oncology 2013139 797-807. (https://doi.org/10.1007/s00432-013-1381-9)

19 Erken E, Koroglu Ç, Yildiz F, Ozer HT, Gulek B \& Tolun A. A novel recessive 15-hydroxyprostaglandin dehydrogenase mutation in a family with primary hypertrophic osteoarthropathy. Modern Rheumatology 201525 315-321. (https://doi.org/10.3109/14397595.2 013.874757)

20 Okten A, Mungan I, Kalyoncu M \& Orbak Z. Two cases with pachydermoperiostosis and discussion of tamoxifen citrate treatment for arthralgia. Clinical Rheumatology 200726 8-11. (https://doi. org/10.1007/s10067-005-1161-2)

21 Li SS, He JW, Fu WZ, Liu YJ, Hu YQ \& Zhang ZL. Clinical, biochemical, and genetic features of 41 Han Chinese families with primary hypertrophic osteoarthropathy, and their therapeutic response to etoricoxib: results from a six-month prospective clinical intervention. Journal of Bone and Mineral Research 201732 1659-1666. (https://doi.org/10.1002/jbmr.3157)

22 Tuysuz B, Yilmaz S, Kasapcopur Ö, Erener-Ercan T, Ceyhun E, Bilguvar K \& Gunel M. Primary hypertrophic osteoarthropathy caused by homozygous deletion in HPGD gene in a family: changing clinical and radiological findings with long-term follow-up. Rheumatology International 201434 1539-1544. (https://doi. org/10.1007/s00296-014-3037-8)

23 Yuan L, Liao R, Lin Y, Jiang Y, Wang O, Li M, Xing X, Pang Q, Hsieh E \& Xia W. Safety and efficacy of cyclooxygenase-inhibition for treatment of primary hypertrophic osteoarthropathy: a singlearm intervention trial. Journal of Orthopaedic Translation 2018 [epub]. (https://doi.org/10.1016/j.jot.2018.10.001)

24 Niesen FH, Schultz L, Jadhav A, Bhatia C, Guo K, Maloney DJ, Pilka ES, Wang M, Oppermann U, Heightman TD, et al. High-affinity inhibitors of human NAD-dependent 15-hydroxyprostaglandin dehydrogenase: mechanisms of inhibition and structure-activity relationships. PLoS ONE 20105 e13719. (https://doi.org/10.1371/ journal.pone.0013719)

25 Yuan L, Chen L, Liao RX, Lin YY, Jiang Y, Wang O, Li M, Xing XP, Pang QQ, Jiajue R, et al. A common mutation and a novel mutation in the HPGD gene in nine patients with primary hypertrophic osteoarthropathy. Calcified Tissue International 201597 336-342. (https://doi.org/10.1007/s00223-015-0024-3)

26 Nomura T, Lu R, Pucci ML \& Schuster VL. The two-step model of prostaglandin signal termination: in vitro reconstitution with the prostaglandin transporter and prostaglandin 15 dehydrogenase. Molecular Pharmacology 200465 973-978. (https://doi.org/10.1124/ mol.65.4.973)

27 Hou Y, Lin Y, Qi X, Yuan L, Liao R, Pang Q, Cui L, Jiang Y, Wang O, $\mathrm{Li} \mathrm{M}$, et al. Identification of mutations in the prostaglandin transporter gene SLCO2A1 and phenotypic comparison between two subtypes of primary hypertrophic osteoarthropathy (PHO): a singlecenter study. Bone 2018106 96-102. (https://doi.org/10.1016/j. bone.2017.09.015)

28 Tariq M, Azeem Z, Ali G, Chishti MS \& Ahmad W. Mutation in the HPGD gene encoding $\mathrm{NAD}^{+}$dependent 15-hydroxyprostaglandin dehydrogenase underlies isolated congenital nail clubbing (ICNC). Journal of Medical Genetics 200946 14-20. (https://doi.org/10.1136/ jmg.2008.061234)

29 Yuksel-Konuk B, Sirmaci A, Ayten GE, Ozdemir M, Aslan İ, YilmazTuray Ü, Erdogan Y \& Tekin M. Homozygous mutations in the 15-hydroxyprostaglandin dehydrogenase gene in patients with primary hypertrophic osteoarthropathy. Rheumatology International 200930 39-43. (https://doi.org/10.1007/s00296-009-0895-6)
30 Sakai T, Hatano Y, Matsuda-Hirose H, Nishiyori R \& Fujiwara S. Atopic dermatitis-like dermatitis emerges unevenly on different sites in flaky tail mice. Journal of Dermatological Science 201578 151-153. (https://doi.org/10.1016/j.jdermsci.2015.01.008)

31 Khan AK, Muhammad N, Khan SA, Ullah W, Nasir A, Afzal S, Ramzan K, Basit S \& Khan S. A novel mutation in the HPGD gene causing primary hypertrophic osteoarthropathy with digital clubbing in a Pakistani family. Annals of Human Genetics 201882 171-176. (https://doi.org/10.1111/ahg.12239)

32 Krook M, Marekov L \& Jornvall H. Purification and structural characterization of placental NAD(+)-linked 15-hydroxyprostaglandin dehydrogenase. The primary structure reveals the enzyme to belong to the short-chain alcohol dehydrogenase family. Biochemistry 199029 738-743. (https://doi. org/10.1021/bi00455a021)

33 Jornvall H, Persson B, Krook M, Atrian S, Gonzalez-Duarte R, Jeffery J \& Ghosh D. Short-chain dehydrogenases/reductases (SDR). Biochemistry 199534 6003-6013. (https://doi.org/10.1021/ bi00018a001)

34 Adams B, Amin T, Leone V, Wood M \& Kraft JK. Primary hypertrophic osteoarthropathy: ultrasound and MRI findings. Pediatric Radiology 201646 727-730. (https://doi.org/10.1007/ s00247-016-3544-8)

35 Giancane G, Diggle CP, Legger EG, Tekstra J, Prakken B, Brenkman AB, Carr IM, Markham AF, Bonthron DT \& Wulffraat N. Primary hypertrophic osteoarthropathy: an update on patient features and treatment. Journal of Rheumatology 201542 2211-2214. (https://doi.org/10.3899/jrheum.150364)

36 Diggle CP, Carr IM, Zitt E, Wusik K, Hopkin RJ, Prada CE, Calabrese O, Rittinger O, Punaro MG, Markham AF, et al. Common and recurrent HPGD mutations in Caucasian individuals with primary hypertrophic osteoarthropathy. Rheumatology 201049 1056-1062. (https://doi.org/10.1093/rheumatology/keq048)

37 Jajic Z, Jajic I \& Nemcic T. Primary hypertrophic osteoarthropathy: clinical, radiologic, and scintigraphic characteristics. Archives of Medical Research 200132 136-142. (https://doi.org/10.1016/S01884409(01)00251-X)

38 Pineda C. Diagnostic imaging in hypertrophic osteoarthropathy. Clinical and Experimental Rheumatology 199210 (Supplement 7) 27-33.

39 Sugimoto Y \& Narumiya S. Prostaglandin E receptors. Journal of Biological Chemistry 2007282 11613-11617. (https://doi. org/10.1074/jbc.R600038200)

40 Inada M, Takita M, Yokoyama S, Watanabe K, Tominari T, Matsumoto C, Hirata M, Maru Y, Maruyama T, Sugimoto Y, et al. Direct melanoma cell contact induces stromal cell autocrine prostaglandin E2-EP4 receptor signaling that drives tumor growth, angiogenesis, and metastasis. Journal of Biological Chemistry 2015290 29781-29793. (https://doi.org/10.1074/jbc. M115.669481)

41 Mandal PK, Freiter EM, Bagsby AL, Robertson FM \& McMurray JS. Efficient synthesis of apricoxib, CS-706, a selective cyclooxygenase-2 inhibitor, and evaluation of inhibition of prostaglandin E2 production in inflammatory breast cancer cells. Bioorganic and Medicinal Chemistry Letters 201121 6071-6073. (https://doi. org/10.1016/j.bmcl.2011.08.050)

42 Cho H, Walker A, Williams J \& Hasty KA. Study of osteoarthritis treatment with anti-inflammatory drugs: cyclooxygenase-2 inhibitor and steroids. BioMed Research International 20152015595273. (https://doi.org/10.1155/2015/595273)

Received in final form 14 April 2019

Accepted 7 May 2019

Accepted Preprint published online 7 May 2019 https://ec.bioscientifica.com https://doi.org/10.1530/EC-19-0149 (c) 2019 The authors Published by Bioscientifica Ltd

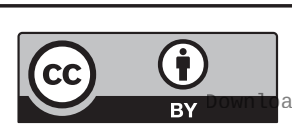

This work is licensed under a Creative Commons Attribution 4.0 International License. ded from Bioscientifica.com at 04/26/2023 08:30:01AM 